\title{
Research on Cloud Classroom of Simulated Audit's Virtual Teaching Platform
}

\author{
Li Zhang \\ School of Information Management \\ Beijing Information Science \& Technology University \\ Beijing, 100192, China \\ yeszhl@163.com
}

\begin{abstract}
The rapid development of MOOC and flipped classrooms have raised higher requirements in cultivating of talents in the digital economy era. In order to develop high quality auditing talents who have good knowledge of auditing theory, have the technology of information risk assessment and processing in complex information environment. This article analyzes the new challenges faced by the auditing personnel in the digital economy era, and points out that the major of auditing education in the college can establish the audit project library and project-driven establish audit simulation field. Using the audit cloud education platform for teaching content, teaching mode and teaching method reform to adapt to the major audit course of the construction of the new requirements in the digital economy era and enhance the audit ability of talents cultivation.
\end{abstract}

Keywords-Project driven, Simulation audit, Flipped classroom, Cloud platform, Teaching method

In recent years, cloud computing has become a new technological revolution following the personal computer and internet in the world. Under the leadership of Google, Amazon, IBM, Microsoft, Alibaba and other well-known cloud computing pioneer at home and abroad, cloud computing is spawning a new business model of cross-industry integration, and reconstructing the eco-chain of the IT industry, even the global economic form.

Cloud computing highly integrates a variety of technologies, bringing great changes of the audit environment. At the same time, it also puts forward a sharp problem in the audit professional talents training. For example, How to solve the contradiction between the traditional audit professional curriculum system, teaching content and the lack of experimental resources? How to make students thoroughly recognize the new requirements of the modern risk - oriented audit theory on audit skills in the digital economy era? How does audit teaching method adapts to the new challenge of audit personnel training in the digital economy era?

\section{OVERVIEW}

Cloud computing improves the utilization of computing resources with a low cost, and it is accelerating the transformation of traditional industries, and promotes the transformation of traditional service providers. The field of education is also rapidly changing to meet the needs of the new era. $\mathrm{Mu} \mathrm{Ke}$ (MOOC), flipped classroom, cloud classroom, rain classroom teaching are the new achievements of rapid integration between Classroom education and cloud computing technology in recent years, greatly promoting the new development of the field of education.

MOOC is one of the most representatives of the teaching changes. The first MOOC platform is considered to be the Artificial Intelligence Graduate Program which belongs to a professor named Bastien Shilangat at Stanford University in 2011, which attracts over 160,000 students from more than 190 countries and territories on the Internet. In 2012, the top universities in the United States set up some online learning platforms such as Coursera, Udacity, Edx. These providers of three courses provide free courses online to promote the development of online courses. In 2013, Tsinghua University, Fudan University, Shanghai Jiaotong University actively cooperate with Edx, Coursera, providing online courses for the world. In 2013, the MOOC Academy was launched on the line. In 2014, NetEase Yunyun undertook the national boutique open course task of the Ministry of Education, and launched the "MOOC" project of China University.

Flipped classroom is teaching modes which transfers the right of decision in learning from the teacher to the student and re-adjusts the teaching mode time which inside and outside the classroom. In this teaching mode, teachers no longer occupy the classroom time to teach information, but by the students focusing on active project-based learning. They study the solutions together to get a deeper understanding of the theory of knowledge. Students complete self-study after class, through access to information, watching video lectures, listening podcast, participating in web discussions. They can independently plan their learning content, rhythm and the way of knowledge presented. Teachers use lectures and collaborative methods to meet the needs of students and promote their personalized learning. Flipped classroom model make learning more interesting and more flexible by active practice and Make the students more involved.

The Internet Age, especially the Mobile Internet, Promotes the Reform of the Teaching Mode of "MOOC" and "Flipped Classroom" in College Classroom Teaching. Stephen Hagrid, Wang Baohua(2014) argues that the view of MOOC's view points out the disagreement of educational institutions and MOOC its potential for higher education threat through a comprehensive analysis of the recent literature on MOOC and open distance learning. MOOC through the introduction of a new set of design is changing the concept of education. 
Through the co-word analysis of the high-frequency keywords in the MOOC research literature in recent years, Yayuan Li(2015) concluded that the study on the MOOC should be changed from the "paradigm" to the "paradigm" in the future and we should pay attention to practice, promote the country, society, school to collaboratively innovate. Through the auditing flipped classroom, Yuna $\mathrm{Si}(2016)$ and others established the multiple evaluation system of four levels of assessment based on the usual grades, practical ability, case analysis, volume test . Wenjun Li. (2015) initially constructed the flipped classroom teaching system based on the teaching design, teaching resources and teaching evaluation.

At home and abroad on the MOOC and flipped classroom in teaching design, teaching programs, evaluation system is rich. The combination of theoretical practice of the specific operational program is not clear, and the deployment of teaching resources and other technical path there is a weak link. Therefore, the article will be on the necessary of audit cloud classroom construction, project-driven simulation audit flipped classroom program design, audit cloud classroom deployment and delivery research.

\section{THE DEVELOPMENT OF INFORMATION TECHNOLOGY FORCED AUDIT TEACHING REFORM}

With rapid development of cloud computing in the world, organizations, enterprises have gradually completed the construction of data centers and they prepare to improve resource utilization by using virtualized technology. The comprehensive application of information technology changes the audit environment in a qualitative way: The audit object extends to information system which provides financial data and even financial cloud; Transmitting accounting information by internet increases the risk of audit. Therefore, what kind of methods and techniques it use? And how to develop highquality applied audit talents who grasping information technology? It is a problem that must be solved in the major of auditing (computer audit)

Audit Practice and Case Analysis is one of the professional compulsory courses of auditing major, it is a course that combined auditing theory with auditing practice, and it is also the core course of auditing, accounting and other major about finance and Economics. In general, the major of computer audit in Information Management College will open the course, such as Audit Simulation Practice, Internal Audit, and Computer Audit, after Fundamentals of Auditing. Therefore, the Audit Practice and Case Analysis play a guiding role in the entire audit discipline teaching system. In the aspect of audit theory, Audit Practice and Case Analysis try to reflect the new achievements in the field of auditing; in the aspect of practice, it is closely around the practical, applied talents training.

In the process of teaching, students generally think that it is difficult to learn audit: the audit theory and knowledge is too abstract, the auditing standards and practice changes too rapid, and the audit is closely related to accounting, tax law and other laws and regulations. Even the students who have studied 64 theoretical classes and 40 simulation experiments are still unable to carry out the audit work and do not compile the audit work papers. Where is the problem? Classic teaching materials and curriculum design of "audit practice and case analysis" emphasis are main on abstract theory, terminology and guidelines introduced. It is hard for students to understand and imagine. Even if the students learned the knowledge on the book, it is difficult for them to practice in the specific operation.

"Audit practice and case analysis" currently uses 56+8 syllabus; It consists of 56 theoretical lectures and 8 experiments. Students learn more about theoretical knowledge, but they are lack of enthusiasm on learning and lack of better teaching project and teaching methods for the cultivation of practical ability.

In the view of the above reasons, it is urgent to design a set of practical teaching methods which make the students experience and participate in the audit practice.

\section{PROJECT DRIVEN SimUlation AUdit FliPPED ClassRoOM}

The reform ideas of simulated audit cloud classroom of project driven: the audit case database was established effectively on the basis of using early teaching reform and the simulation audit platform was researched and developed., the design of a set of complete audit projects reveal the real restoration of the audit site, audit classroom teaching neatly use teaching methods with a clear audit mission-driven, group discussions, personal statements, teacher reviews, group competition, the audit site integrated simulation by using the audit cloud platform. Students actively complete the task through the access to information, online communication and open experiment. Establishing the flipped classroom through the project-driven, cloud platform provides a virtual simulation of audit resources and services, audit practice and case analysis courses for the audit cloud classroom, which effectively improve students' learning enthusiasm and reinforce the student audit theory and practice skills.

\section{A. Simulated audit project design}

After the real audit case is instead, Course leader will establish audit simulation projects, and strive to restore the audit site from the company's background, audit requirements, to electronic data and accounting statements. Students are required to complete the whole process of audit site, from bidding after calling for bids, the formation of the company, complete bidding, bidding, design of audit plan, risk assessment of material misstatement, to the form of audit papers, obtain of audit evidence according to the audit report. Combining the audit theory with practice, enhance students' sense of participation, so that each student has the task and each task flip classroom with Problem-oriented.

\section{B. Present audit application using the electronic data of the previous curriculum}

In the case of teaching, deeply combining the computer aided audit method and the five cycle audit theoretical, using the data of accounting information system on the experimental that semester students completed, according to the different five cycle audit goal, it enables students to understand the depth of the accounting information system business processes, data flow and the logical relationship. Students can find the audit doubts by business logic and deeply identify audit doubts by database technology. 
In the process of audit evidence collection, through the preparation of the manuscript, students will closely integrate electronic data, audit methods and accounting documents to enhance the operation ability from the theory to practice. From the case to the data, students successfully achieve conversion from the theory to the practice through the project design and data development. Audit theory will present using projects, data, and books. The passive acceptance will become active learning.

\section{Using existing research results to achieve technological breakthroughs}

The system of audit case database and audit method library has been constructed in 2011, which make students learn from expert experience in similar problems. The project is based on the national science and technology support program For The National Audit "Immune System "Audit Simulation And Simulation Platform Research and Development and Application Demonstration Project, it shows that the simulation audit system builds audit cloud classroom. It provides case learning, integrated training environment for students through the audit learning simulation platform and audit practice simulation platform. In the simulation audit practice platform, students set up project team and complete the audit project with the team to enhance their teamwork ability.

\section{The Audit Cloud ClassRoom DePloyment AND DELIVERY}

In order to solve the contradiction between the resources and the demand of the experimental teaching resources in modern colleges and universities, the simulation audit cloud classroom uses cloud computing technology and put forward Design and implementation scheme of audit simulation platform, based on cloud computing and virtualized technology, targeting the audit simulation business status, facing to the design difficulties of functional requirements.

Through audit simulation platform, audit cloud classroom provides the main system including audit simulation business-Audit learning simulation platform, audit practice simulation platform, backstage management system, virtualized construction management system, and a variety of middle ware and system used by audit simulation services. Audit cloud classroom provides teachers and students unified authentication login, students can learn in the audit simulation learning platform to achieve study in the open audit classroom; Comprehensive practice of grouping tasks is realized in the audit practice simulation platform; The integrated management platform for different systems and different applications, including different middleware and systems used in the existing audit simulation service is realized. On the basis of taking the feasibility, compatibility, expansibility and efficiency of the system components in to account, the platform can realize the discovery, composition and invocation of service components. The platform makes full use of the advantages of SOA encapsulation, loose coupling, and reusability, using service interface independent of hardware platform, operating system and programming language. With Building service components in a unified and common way, the platform realizes component invocation and interaction based on demand and service oriented among different systems.
The platform uses Web Service technology to design and encapsulate the system components into service, realize the discovery, combination and call of the service components between the different systems, and complete the creation, deployment and management of the virtual machine and transfer of the application data in different systems and different applications components. At the same time, it provides support for the service extension of the audit simulation service middleware, which is conducive to the data transmission and integration between heterogeneous systems. (As shown in Fig. 1)

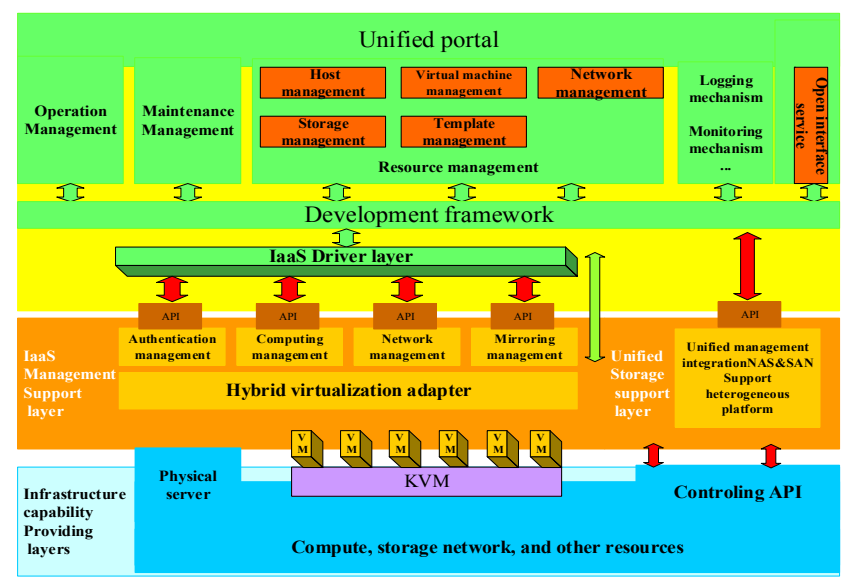

Fig. 1. Audit Simulation Platform Technology Architecture

The auditing cloud classroom realizes the efficient dispatching of auditing resources in information auditing, the automatic deployment of audit environment and the adaptive management of computing resource pool, and transforms the application framework and application demonstration of traditional auditing in new technologies such as cloud computing and virtualized Breaking the original audit environment and the use of hardware and software resources. It is conducive to improving the efficiency of audit resources, optimizing the audit method, and enhancing the audit results. Audit and simulation business personnel can be more specialized in their own business closely relating audit simulation, which shorten the time to enter the simulation audit business. Hardware and software resources are transparent, which make it possible for the audit staff to access and implementation of audit simulation business at different time, different locations, and different equipment's. It is convenient to manage hardware and hardware resources. Audit cloud classroom achieves the unified certification of hardware and software resources of audit simulation, achieves rapid development, deployment and distribution of audit platform simulation, and provides hardware resources dynamic allocation scheduling on demand.

Through cloud computing and virtualized technologies, Auditing cloud classes implements adaptive management and deployment of IaaS, SaaS in audit the business environment and the resource pool, it is effectively allocates computing resources for the users. In order to ensure the performance and efficiency of the audit business, the business requirements of 
the audit system are abstracted. Through the construction of two modules of application delivery and platform (operating system, database) delivery, the audit cloud classroom completes virtualized integration of software and system and achieves rapid and flexible deployment of audit environment. In addition, taking the future development and the demand expansion of the system into account, the project can be carried in design, development and deployment of audit application on the PaaS layer.

\section{THE EFFECT AND SIGNIFICANCE OF AUDIT CLOUD CLASSROOM}

Simulation audit cloud classroom based on project driven in the " audit practice and case analysis" carries out reform of teaching method .Through putting the audit theory by the way of audit project into the teaching process, using virtual teaching platform to share the audit results, using collective wisdom to enhance learning efficiency, audit cloud classroom is helpful to improve student initiative and improve student learning efficiency.

In the past two years, with on-site observation and afterschool feedback, students have greatly changed from the original class absentee to aggressiveness. They use weekend to the library for accessing to information, group discussion, and actively preparing to speak. Their enthusiasm for learning is very high.

The teaching method of project driven audit simulation flipped classroom greatly enriches the students' cognitive ability, improves the initiative of students active learning, and Stimulates students' creative thinking. Using the simulated audit cloud platform by virtual resource pool integrated services, the simulated audit cloud class improves the utilization efficiency of experimental resources and avoids students to install a variety of audit software on a personal computer. Through the open network, we can grasp the basic knowledge, theories and skills of modern audit more convenient in the field of simulated audit. So that students have the practical ability of making appropriate audit judgment, investigation and confirmation, and specific treatment to the financial fraud of complex, significant and concealment

\section{CONCLUSIONS AND PROSPECTS}

The digital economy era puts forward higher requirements for the cultivation of audit talents. By establishing a model of audit project, Simulated audit cloud classroom based on task driven guides to flip the classroom teaching reform and uses our school's scientific research results---the simulation auditing platform provides auditing cloud classroom, provides the open network course and the comprehensive training resource deployment with the virtual interactive mode. The comprehensive utilization of the experimental resources can effectively improve the enthusiasm and initiative of the students. It is helpful to cultivate the audit talents that have modern audit theory, technology and methods.

\section{ACKNOWLEDGMENT}

This article thanks National Natural Science Foundation (61572079), the Beijing Information Technology University 2015 curriculum construction Project, (2015KGYB31), Beijing Information Technology University 2016 teaching reform project (2016JGYB26) and the Beijing Information Technology University promotes the university connotation development-teaching reform project (5111723601).

\section{REFERENCES}

[1] Large open network course [N]. Baidu entry. Http://baike.baidu.com [reference date 2017-04-03] (In Chinese).

[2] Pan Yantao, Liao Yunyun. The trend of "Mu" in the information literacy education for College Students[J] Journal of University Library,2014,(04):21-27. (In Chinese)

[3] Flipped Classroom [N]. Baidu entry. http://baike.baidu.com [reference date2017-04-03]. (In Chinese)

[4] Stephen Hagd, Wang Baohua, He Yi. Mu lesson is mature [J]. education research, 2014, (05): 92-99+112. (In Chinese)

[5] Li Wei. Review on the current situation of domestic studies on mu ke (MOOC): hot topics and trends: common visualization analysis based on keywords from 2009 to 2014 CNKI [J]. audiovisual education research, 2015, (55-60.). (In Chinese)

[6] Si Yuna, Yin Wei. Study on the flipped classroom and multiple evaluation system of auditing [J]. Modern economic information, 2016: 424-425. (In Chinese)

[7] Li Wenjun, Wang Haibing. Research on the reform of the teaching model of "audit basis" based on the concept of flipped classroom [J]., 2015, (51): 135.(In Chinese) 